\title{
Aggression in Boys and Girls as Related to Their Academic Achievement and Residential Background
}

\author{
Md Shahinoor Rahman, Lailun Nahar \\ Department of Psychology, University of Chittagong, Chittagong, Bangladesh \\ Email: shahinpsy@cu.ac.bd \\ Received February $1^{\text {st }}, 2013$; revised March $4^{\text {th }}, 2013$; accepted April $3^{\text {rd }}, 2013$
}

\begin{abstract}
Copyright (C) 2013 Md Shahinoor Rahman, Lailun Nahar. This is an open access article distributed under the Creative Commons Attribution License, which permits unrestricted use, distribution, and reproduction in any medium, provided the original work is properly cited.
\end{abstract}

\begin{abstract}
The study was conducted to explore aggression in boys and girls as related to their academic achievement and residential background in Bangladesh. Stratified random sampling technique was used and total 80 respondents constituted the sample of the study. They were equally divided into boys and girls. Each group was again equally divided into high and low grade. Each subgroup was again equally divided into urban and rural residential background. Thus the study used a $2 \times 2 \times 2$ factorial design consisting of two levels of gender (boy/girl), two levels of academic achievement (high grade/low grade) and two levels of residential background (urban/rural). The Bengali version of measure of aggressive behavior (Rahman, A. K. M. R., 2003) originally developed by Buss and Perry (1992) was used for the collection of data. It was found that regardless of gender, boys expressed more aggression than girls. Similarly, regardless of academic achievement, students with high academic grade will show more aggressive behavior than low academic grade students. Finally, students of urban areas will not show significantly more aggressive behavior than rural areas students. Thus the differential treatment in gender, academic achievement and residential background provides a new dimension in understanding aggression in rural and urban boys and girls.
\end{abstract}

Keywords: Aggression; Academic Achievement; Residential Background

\section{Introduction}

Aggression is an overt behavior of a person that intended to harm another person physically or psychologically or to damage or destroy or take that person's property. According to Baron (1994) aggression is any form of behavior directed toward the goal of harming or injuring another living being who is motivated to avoid such treatment. Aggression viewed as a form of behavior. The outcome of aggressive behavior is a very common phenomenon of our daily life. Considering social, political and religious context, aggression is seen as a natural system. Most of the time people show aggressive behavior for predominant each others. In the family it is very as usual matter. For example, clash between husband and wife, father and son, and dominating one person to other. It simply reminds us that aggression has a biological and social basis. Thus, aggressive behavior in humans, for example, threat, attack and defense, are commonly related to competition over resources. Moreover, some environmental factors associated with the cause of aggression like crowding (Kaya \& Erkip, 2001), noise (Geen \& O’Neal, 1969) and density. Thus, home environment may have any effect on aggression. Considering above matter this study on aggression in boys and girls as related to their academic achievement and residential background is framed.

The present world-view experiences aggression repeatedly in individual life as well as in national and international areas. USDJ (2012) reported 1,203,564 crimes of violence in 2011. In the same year, there were 83,425 forcible rapes and 751,131 assaults that resulted in injury to the victim. USGAO (2011) reported more than 5 children die every day as a result of child abuse. Harlow (1999) reported that family members were the primary abusers of the men: a parent, guardian, or other relative was identified by $57 \%$ to $70 \%$.

In Bangladesh, violence is a common phenomenon and it increases day by day. In 2007, more than half of married women aged 15 - 49 experienced physical violence from their husbands (NIPORT, 2009). ASF (2012) reported that since 1999 to 2011, total 3321 person were victimized acid violence, among these victim 818 were children, 812 were men and 1689 were women. Eve teasing and rape are another type of violence against women in Bangladesh. Approximately 13,000 women were the victim of eve teasing in 2010 (Masum, 2012) and more than 3092 were raped in 2012 (Police, 2013). A considerable part of these violence, terrorism and rape prevailing in the country are alarming for future generation for comfortable livings on this earth. They confirm a basic lesson of human history that aggression exists everywhere in our individual, social, national or international life. The present study was an empirical investigation aimed at exploring the phenomenon of aggression in boys and girls as related to academic achievement and residential background in Bangladesh.

Several studies showed that poor academics predicted bad behavior, which hampered academic progress (Chen et al., 2010; Christle, Jolivette, \& Nelson, 2005; Schwartz, Chang, \& Farver, 2001). Connor (2004) found a strong association between academic failure and aggression. Johnson (2009) in his 
research showed that an overall low average was a better predictor for the likelihood of a student displaying aggression at school than was a specific learning disability label. Chen and his associate (2010) found their research that aggression had unique effects on later social competence and academic achievement. Stipek and Miles (2008) found relationship between aggression and achievement is complex and reciprocal. Schwartz et al. (2006) found adolescents who were highly aggressive, increases in popularity were associated with increases in unexplained absences and decreases in grade point average. Chen et al. (1997) found that academic achievement predicted children's social competence and peer acceptance. They also found children's social functioning and adjustment, including social competence, aggression-disruption, leadership, and peer acceptance, uniquely contributed to academic achievement. Anderson and Dill (2000) found their study that real-life violent video game play was positively related to aggressive behavior and delinquency. They also showed stronger relation for individuals who are characteristically aggressive and for men. Academic achievement was negatively related to overall amount of time spent playing video games. Hoover et al. (1992) found competitiveness and regimentation have also been blamed in part for an increase in the rate of students' aggressive behaviour in Japan. Mukerjee and Dagger (1990) claimed that leisure boredom may be correlated to an increase in adolescent participation in crime. However, Barriga and his associate (Barriga et al., 2002) showed aggressive behavior syndromes exhibited significant zero-order correlations with the academic achievement measures.

\section{Objectives of the Study}

- The main objective of this study is to determine the effect of aggression on sex, academic achievement and residence.

- Second objective of this study is to find out the consistency of the recent study of aggressive behavior with previous research.

- Final objective is to search for some predisposing causes of aggression and to explain their moderating effects.

\section{Rationale of the Study}

According to Social learning theory of aggression, People want to acquire self respect, to become supreme, to avoid feeling of inferiority complex and try to dominate others in social life, household life and national or even in universal life. In this aspect the students of higher grade will try to dominate lower grade students and students of urban will try to dominate rural students showing more aggressive behavior. On the basis of this logic, following hypotheses were framed.

$\mathbf{H}_{1}$ : Boys will show more aggressive behavior than Girls.

$\mathbf{H}_{2}$ : Students with high academic grade will show more aggressive behavior than low academic grade students.

$\mathbf{H}_{3}$ : Students of urban areas will show significantly more aggressive behavior than rural areas students.

\section{Materials and Methods}

\section{Sample}

The sample of present study was constituted of 80 respondents and equally divided into boys and girls. Each category was again divided into high and low academic grade. Each subgroup was then equally divided into urban and rural residential background. A stratified random sampling procedure was taken for the collection of data from different department of Chittagong University. They were between 20 - 25 years old.

\section{Instrument}

The Bengali version of Measure of Aggressive Behavior (Rahman, A. K. M. R., 2003) originally developed by Buss and Perry (1992) was used for data collection. It contains 25 items and was divided into 5 dimensions such as physical aggression (five items), verbal aggression (nine items), hostile aggression (five items), anger aggression (three items) and indirect aggression (three items). Hypothetical situations were constructed on each item. Each item was followed by 5 alternatives ranging from totally true to totally false. Totally true was given 5 points, true was given 4 points, neutral was given 3 points, false was given 2 points and totally false was given 1 point. The Highest Possible Score (HPS) was $25 \times 5=125$ and the Lowest Possible Score (LPS) was $25 \times 1=25$. A score following on 75 or above was regarded as Aggressive Behaviour Score. Its coefficient alpha is 0.89 and test-retest reliability is 0.80 . The Measure of Aggressive Behaviour was confirmed by validation at several stages.

\section{Design of the Study}

The present study used a $2 \times 2 \times 2$ factorial design consisting of two levels of gender (boy/girl), two levels of academic achievement (high grade/low grade) and two levels of residential background (urban/rural). Analysis of Variance (ANOVA) was computed on total scores of the MAB. Three independent variables such as 1) gender, 2) Academic achievement and 3) residential background were used. Thus, a three-way ANOVA involving two levels of gender, two levels of academic achievement and two levels of residential background was computed.

\section{Results}

The summary of ANOVA has been presented in Table 1 . The results on total score of MAB showed that the main effect for gender and academic achievement is statistically significant $(p<0.01)$. A three-way interaction involving gender, residential background and academic achievement is statistically signifycant $(p<0.01)$.

The results of ANOVA shows (Table 1) significant main effect for gender $(\mathrm{F}=122.18, \mathrm{df}=1 / 72, p<0.01)$. An inspection of mean scores (Table 2) shows that regardless of gender, the male respondents $(\mathrm{M}=71.70)$ expressed significantly higher aggression as compared to female respondents $(M=63.30)$. Similarly, ANOVA shows (Table 1) significant main effect for Academic achievement $(\mathrm{F}=18.29$, df $=1 / 72, p<0.01)$. An inspection of mean scores (Table 2) shows that regardless of academic achievement, the high grade respondents $(M=69.13)$ expressed significantly higher aggression as compared to low grade respondents $(\mathrm{M}=65.95)$.

Gender $\times$ Academic achievement $\times$ Residential Background: The results of ANOVA shows (Table 1) significant interaction effect for gender, academic achievement and residential background $(\mathrm{F}=7.35, \mathrm{df}=1 / 72, p<0.01)$. In case of high academic grade, it shows (Table 3 ) that rural boys respondents (74.50) 
Table 1.

Summary of the Anova involving gender, academic achievement and residential background on the total scores of the MAB.

\begin{tabular}{ccccc}
\hline Sources of variance & SS & df & MS & F \\
\hline $\begin{array}{c}\text { Gender (A) } \\
\text { Academic } \\
\text { achievement (B) }\end{array}$ & 1411.2 & 1 & 1411.2 & $122.18^{*}$ \\
Residence (C) & 12.8 & 1 & 12.80 & $1.10 \mathrm{~ns}$ \\
AB & 1.25 & 1 & 1.25 & $0.10 \mathrm{~ns}$ \\
AC & 24.15 & 1 & 24.15 & $2.09 \mathrm{~ns}$ \\
BC & 1.25 & 1 & 1.25 & $0.10 \mathrm{~ns}$ \\
ABC & 84.95 & 1 & 84.95 & $7.35^{*}$ \\
Error & 832.10 & 72 & 11.55 & \\
Total & 2579 & 79 & & \\
\hline
\end{tabular}

Note: $n s=$ Not Significant, ${ }^{*} p<0.01$.

expressed significantly more aggression as compared to urban boys respondents (72.40). However, urban girl respondents (66.90) expressed significantly more aggression as compared to rural girl respondents (62.70). In case of low academic grade, it is seen that there is no significant difference among boys of urban and rural respondent and girls of urban and rural respondent.

In case of urban, it has found that girls with high academic grade (66.90) expressed significantly more aggression as compared to low academic grade respondents (61.60). But no significant difference is found between boys with high and low academic grade respondents. Similarly, In case of rural, boy respondents with high academic grade (74.50) expressed significantly more aggression as compared to boy respondents with low academic grade (69.20). However, no significant difference is seen between girls with high and low academic grade respondents of rural areas.

After analyzing means of different groups, it has seen that there is a contrast pattern of aggressive behavior both in boys and girls. In case of boys, there is no different between high and low academic grade of urban respondents. But, high academic grade respondents showed more aggressive behavior than low academic grade of rural respondents. Contrary, In case of girls, there is no different between high and low academic grades of rural respondents. But, significant different have found in high and low academic grade of urban respondents.

The findings of the study may be summarized as follows:

1) The main effect of academic grade and gender was significant.

2) The interaction effect of gender, academic achievement and residence was significant.

3) Boys are more aggressive than girls.

4) Respondent with high academic grade is more aggressive than respondent with low academic grade.

5) Boys with high academic grade of rural areas are more aggressive than boys with high academic grade of urban areas.

6) Girls with high academic grade of urban areas are more aggressive than girls with high academic grade of rural areas.

7) In rural areas, Boys with high academic grade are more aggressive than boys with low academic grade.
Table 2.

Showing overall mean scores and significant mean differences between gender and academic achievement on the total scores of the MAB.

\begin{tabular}{ccc}
\hline Parameters & Respondents & Mean scores \\
\hline \multirow{2}{*}{ Gender } & Male & 71.70 \\
& Female & 63.30 \\
Academic achievement & High grade & 69.13 \\
& Low grade & 65.95 \\
\hline
\end{tabular}

Note: Mean difference was computed using Newman-Keuls formula.

Table 3.

Showing overall mean scores and significant mean differences between gender, socio-economic status and residential background on the tota scores of the MAB.

\begin{tabular}{cccc}
\hline Gender & Residential background & \multicolumn{2}{c}{ Academic achievement } \\
\hline \multirow{2}{*}{ Boy } & Urban & High grade & Low grade \\
& Rural & $72.40 \mathrm{a}$ & $70.70 \mathrm{a}$ \\
\multirow{2}{*}{ Girl } & Urban & $74.50 \mathrm{~b}$ & $69.20 \mathrm{a}$ \\
& Rural & $66.90 \mathrm{c}$ & $61.60 \mathrm{~d}$ \\
\hline
\end{tabular}

Note: Mean difference was computed using Newman-Keuls formula.

8) In urban areas, Girls with high academic grade are more aggressive than boys with low academic grade.

\section{Discussion}

The present study was primarily design to observe the effect of gender, academic achievement and residence on aggression and whether these effect decrease or increase the aggressive behavior. The analysis of result has reported that our first and second hypotheses were supported objectively but third hypothesis was not supported by our result. But, overall analyses have reported that our third hypothesis is supported partially.

In first hypothesis, it was said that boys will show signifycantly more aggressive behavior than girls. The analysis reported on the basis of academic achievement and residence, boys exposed significantly more aggressive behavior than girls. This result supported our hypothesis. Our findings is contradict with Rahman and Huq (2005) in the context of Bangladesh. This finding might be explained in the basis of conceptual theory of aggressive behavior. Social learning theory of aggression said that, at the various stages of society, member of it try to dominate each other by means of aggressive behavior as a technique.

In our practical life, it is seen that power full person of the society try to establish predominance over forlorn people using various technique of aggressive behavior. In domestic life, hassle of husband and wife, duel and adversity attitude is driven for self-esteem and self-respect. From the consequence of previous study it has seen that, each society all over the world male shows significantly more aggressive behavior than female (Anderson \& Bushman, 2002). Hence, the theory of aggressive behavior and past research supported our hypothesis. Social, economical, spiritual and cultural context of Bangladesh, it is argued that men are trying to wield on women. Nevertheless 
women at the society try to continue compromising with men anyway. In Bangladesh the outcome of culture and religion has seen that men become the guardian of women in taking social responsibility everywhere. On the other hand women suppose that to secure their responsibility and social security is the social obligation of men. In this perspective we can say that boys want to hold his best position showing aggressive behavior to girls. On the contrary, girls show less aggressive behavior to give the hint that her security and responsibility rely on boys.

In the second hypothesis, it was said that students with high academic grade will show significantly more aggressive behavior than low academic grade students. The analysis shows that student with high academic grade expose more aggressive behavior than low academic grade students. Hence, considering this analysis it can be said that our second hypothesis is supported objectively by our result. This finding might be explained on the basis of social learning theory of aggressive behavior. Accordant to social learning theory, it can be said that aggressive behavior is an art which can help acquire to become supreme. Respondent with high academic grade have came about successful to become best. On the other hand, respondent with low academic grad fall down the lower stage of social status. In this perspective, it can be said that respondent with high academic grade to secure their best social position used strategy of aggressive behavior. On the other hand, respondent with low academic grade stay at lower stage of social status. Then, they show comparatively low aggressive behavior. This result is contradictory with Schwartz and his associate (2006) and Connor (2004) but in the line with Chen $(2010,1997)$.

In third hypothesis, it was said that students of urban areas will show significantly more aggressive behavior than rural areas students. The results reveal that there is no statistically significant difference between urban and rural areas respondents. Then, it can be said that our third hypothesis is not supported by our result. But the interaction effects of gender, academic achievement and residence have found difference significantly. This result indicates that girls with high grade of urban areas expressed more aggressive behavior than that of rural areas girls. With this analysis it can be said that our third hypothesis is supported partially.

In conclusion, it can be said that rural boys with high grade expressed more aggression than urban boys with high grade. Similarly, rural boys with high grade expressed more aggression than boys with low grade. The results of this study have proved that aggressive behavior can be increase or decrease as a function of environment. Considering previous research and the theory of aggressive behavior, it can be explained that, lower class family member shows moderate behavior towards higher class family member as a result of various socioeconomic conditions. To explanation of this matter it can be said that some times, lower class people do not show aggressive behavior towards higher class people to calm down or balance the social environment.

\section{REFERENCES}

Anderson, C. A., \& Bushman, B. J. (2002). Human aggression. Annual Reviews Psychology, 53, 27-51.

doi:10.1146/annurev.psych.53.100901.135231

Anderson, C. A., \& Dill, K. E. (2000). Video games and aggressive thoughts, feelings, and behavior in the laboratory and in life. Journal of Personality and Social Psychology, 78, 772-790. doi:10.1037/0022-3514.78.4.772

ASF (2012). Voice, acid attack statistics. Dhaka: Acid Survivors Foundation.

Baron, R. A., \& Richardson, D. R. (1994). Human aggression. New York: Plenum Press.

Barriga, A. Q., Doran, J. W., Newell, S. B., Morrison, E. M., Barbetti, V., \& Robbins, B. D. (2002). Relationships between problem behaviors and academic achievement in adolescents: The unique role of attention problems. Journal of Emotional and Behavioral Disorders, 10, 233-240. doi:10.1177/10634266020100040501

Buss, A. H., \& Perry, M. P. (1992). The aggression questionnaire. Journal of Personality and Social Psychology, 63, 452-459.

Chen, X., Huang, X., Chang, L., Wang, L., \& Li, D. (2010). Aggression, social competence, and academic achievement in Chinese children: A 5-year longitudinal study. Development and Psychopathology, 22, 583-592. doi:10.1017/S0954579410000295

Chen, X., Kenneth, H. R., \& Li, D. (1997). Relation between academic achievement and social adjustment: evidence from Chinese children. Developmental Psychology, 33, 518-525.

Christle, C. A., Jolivette, K., \& Nelson, C. M. (2005). Breaking the school to prison pipeline: Identifying school risk and protective factors for youth delinquency. Exceptionality, 13, 69-88. doi:10.1207/s15327035ex1302__

Connor, D. F. (2004). Aggression and antisocial behavior in children and adolescents: Research and treatment. New York: The Guilford Press.

Geen, R. G., \& O’Neal, E. C. (1969). Activation of cue-elicited aggression by general arousal. Journal of Personality and Social Psychology, 11, 289-292. doi;10.1037/h0026885

Harlow, C. W. (1999). Bureau of justice statistics selected findings. Bureau of Justice Statistics.

Hoover, J. H., Oliver, R., \& Hazler, R. J. (1992). Bullying: perceptions of adolescent victims in the Midwestern USA. School Psychology International, 13, 5-16. doi:10.1177/0143034392131001

Johnson, C. L. F. (2009). Low academic performance and specific learning disabilities: Determining the better predictor of aggressive behavior at school. Lynchburg: Liberty University.

Kaya, N., \& Erkip, F. (2001). Satisfaction in a dormitory building: The effects of floor height on the perception of room size and crowding. Environment and Behavior, 33, 35-53.

Masum, A. M. (2012). In recent time eve-teasing (sexual harassment) has become major concern in Bangladesh. How far the law and the government have been successful in comparing the issue of eveteasing? Explain and illustrate.

Mukerjee, S. K., \& Dagger, D. (1990). The size of the crime problem in Australia (2nd ed.). Canberra: Australian Institute of Criminology.

NIPORT (2009). Bangladesh demographic and health survey. National Institute of Population Research and Training.

Police, B. (2013). Crime Statistics, Monthly.

Rahman, A. K. M. R. (2003). Psycho-social factors in aggressive behaviour in males and females in Bangladesh. Rajshahi: Rajshahi University.

Rahman, A. K. M. R., \& Huq, M. M. (2005). Aggression in adolescent boys and girls as related to socio-economic status and residential background. Journal of Life and Earth Science, 1, 5-9.

Schwartz, D., Chang, L., \& Farver, J. (2001). Correlates of victimization in Chinese children's peer groups. Developmental Psychology, 37, 520-532. doi:10.1037/0012-1649.37.4.520

Schwartz, D., Gorman, A. H., Nakamoto, J., \& McKay, T. (2006). Popularity, social acceptance, and aggression in adolescent peer groups: Links with academic performance and school attendance. Developmental Psychology, 42, 1116-1127. doi:10.1037/0012-1649.42.6.1116

Stipek, D., \& Miles, S. (2008). Effects of aggression on achievement: Does conflict with the teacher make it worse? Child Development, 79, 1721-1735.

USDJ (2012). Uniform crime report. Washington DC: Federal Bureau of Investigation.

USGAO (2011). Child maltreatment: Strengthening national data on child fatalities could aid in prevention (GAO-11-599). 